\title{
Considerações sobre a operância do psicanalista e a política do ato psicanalítico
}

\author{
Sandra Leticia Berta
}

\begin{abstract}
Resumo
Considerando o ato psicanalítico, a autora revisa e avança sua pesquisa sobre o neologismo de Lacan "operância”, produzido na esteira de suas elaborações sobre $\mathrm{o}$ ato psicanalítico e a Escola. Nessa ocasião, o acento se coloca no litoral entre o desejo do analista e o ato analítico, ambos na dependência lógica da posição que sustenta a operação da transferência, apontada em 1967 com a expressão porte-à-faux. Um percurso nas elaborações em que Lacan avança sobre o objeto $a$, articulando a causa do desejo e o mais-de-gozar, aponta que a operância é efeito do paradoxo do ato e põe à prova tanto a direção da cura quanto a sustentação de um trabalho de Escola, em particular no passe.
\end{abstract}

\section{Palavras-chave:}

Psicanálise; Política; Ética; Operância; Ato psicanalítico.

\section{Considerations on the opérance of the psychoanalyst and the politics of the psychoanalytic act}

\begin{abstract}
Considering the psychoanalytic act, the author revises and advances her research on Lacan's neologism opérance, produced in the wake of his elaborations on the psychoanalytic act and the School. On this occasion, the accent is placed on the coast between the analyst's desire and the analytic act, both in the logical dependence on the position that sustains the transfer operation, pointed out in 1967 with the expression porte-à-faux. A course in the elaborations in which? Lacan advances on the object $a$, articulating the cause of desire and the more-to-enjoy, points out that the opérance is an effect of the paradox of the act and puts to the test both the direction of the cure and the sustention of a School work, in particular when it comes to the pass.
\end{abstract}

\section{Keywords:}

Psychoanalysis; Policy; Ethic; Opérance; Psychoanalytic act. 


\title{
Consideraciones sobre la operancia del psicoanalista y la política del acto psicoanalítico
}

\begin{abstract}
Resumen
Considerando el acto psicoanalítico, la autora revisa y avanza su investigación sobre el neologismo de Lacan “operancia”. En esta ocasión el acento se coloca en las diferencias entre deseo del analista y acto psicoanalítico, ambos en la dependencia lógica de la posición que sostiene la operación de la transferencia, señalada en 1967 con la expresión porte-à-faux. Un recorrido en las elaboraciones que Lacan avanza sobre el objeto $a$, articulando causa de deseo y plus-de-gozar, apunta que la operancia, es el producto de la paradoja del acto y pone a prueba tanto la dirección de la cura como el sostén del trabajo de Escuela, en particular, en el pase.
\end{abstract}

\section{Palabras clave:}

Psicoanálisis; Política; Ética; Operancia; Acto psicoanalítico.

\section{Considérations sur l'opérance du psychanalyste et la politique de l'acte psychanalytique}

\begin{abstract}
Résumé
L'auteur révise et avance ses recherches à propos de l' "opérance " - néologisme de Lacan —, produites à la suite de ses élaborations sur l'acte psychanalytique et l'École, prenant en compte l'acte analytique. Dès lors, l'accent est mis sur les différences entre le désir de l'analyste et l'acte psychanalytique, tous les deux dans la dépendance logique de la position qui soutient l'opération de transfert, signalée en 1967 avec l'expression porte-à-faux. Un parcours dans les élaborations sur lesquelles Lacan avance à propos de l'objet $a$ (en articulant la cause du désir et le plus-de-jouir), et lorsqu'il fait remarquer que l'opérance est le produit du paradoxe de l'acte, mettant à l'épreuve à la fois la direction du traitement et le soutient du travail d'École.
\end{abstract}

\section{Mots-clés :}

Psychanalyse ; Politique ; Éthique; Opérance ; Acte psychanalytique.

Sobre o neologismo de Lacan "operância” do psicanalista, tenho escrito e publicado alguns textos, articulando-o ao objeto $a$, ao desejo do analista e ao ato psicanalítico. Operância, neologismo referente à resposta do analista. A resposta em função entre aquilo que opera e aquilo que produz efeitos no fazer analítico. Hoje, provocada e causada pela participação na Comissão Internacional da Garantia e, 
portanto, fazendo a experiência dos cartéis do passe, volto a essa operância, índice do paradoxo do ato analítico.

No Seminário 15: O ato psicanalítico (Lacan, 1967-1968, inédito), depois de dizer, pela primeira vez, que o inconsciente é "saber sem sujeito", que o ato psicanalítico concerne o sujeito e que a transferência é a colocação em ato do inconsciente, na aula de 22 de novembro, Lacan se pergunta:

$\mathrm{O}$ ato psicanalítico evoca alguma coisa bem diferente, a saber, o ato tal que ele opera psicanaliticamente, isso que o psicanalista dirige da sua ação na operância psicanalítica. Então, aí, é certo, estamos totalmente em outro nível.

- É a interpretação?

- É a transferência à qual somos, assim, remitidos?

- Qual é a essência disso que do psicanalista enquanto operante é ato?

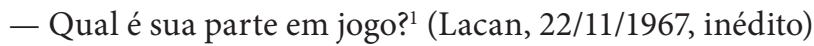

Nesse recorte, a operância psicanalítica lhe permite retomar algumas diferenciações que foram articuladas desde o início de seu ensino: interpretação, transferência, falta-a-ser. Porém, em 1967, a questão do ato incluía a diferença entre a falta-a-ser do psicanalista e o des-ser como produto da queda do sujeito suposto saber. Como pano de fundo, há outra diferenciação em jogo: a tarefa analisante e o ato do psicanalista. É para este último que Lacan aponta quando se pergunta "qual é a essência [palavra certamente estranha nesse contexto] disso que do psicanalista [aqui acentuo o partitivo 'do'] enquanto operante é ato?”. A qual se desdobra na outra questão: qual é sua parte em jogo?

Temos, então, a transferência, a interpretação e o ato. Aqui, evocam-se a tática, a estratégia e a política, propostas em 1958 quando se perguntava pelo desejo do analista, e no qual a política do psicanalista tinha como referente a falta-a-ser. Contudo, no Seminário 15: O ato psicanalítico (Lacan, 1967-1968, inédito), que inicia após escrever a Proposição, a política poderá ser vinculada ao ato. Aí, enlaçam-se ato e Escola a partir da proposta do dispositivo do passe. O âmago da

1 Mais cela peut tout de même aussi, cette conjonction de deux mots : l'acte psychanalytique, nous évoque quelque chose de bien différent, à savoir l'acte tel qu'il opère psychanalytiquement, ce que le psychanalyste dirige de son action dans l'opérance psychanalytique. Alors là bien sûr, nous sommes à un tout autre niveau.

- Est-ce que c'est l'interprétation?

- Est-ce que c'est le transfert à quoi nous sommes ainsi portés?

— Quelle est l'essence de ce qui du psychanalyste en tant qu'opérant est acte?

- Quelle est sa part dans le jeu? 
Escola refere-se especificamente ao que está em jogo na função analista "qual é sua parte em jogo?”. O equívoco linguageiro logo se deixa ouvir: en jeu/en je. Algo desse $J e$, a ser entendido como o sujeito e o inconsciente, pode ligar-se ao em-si do objeto $a$, como indica no Seminário 15: O ato psicanalítico e no Resumo do seminário de 1967-1968 (Lacan, 1969/2003, pp. 371-379). O em-si do objeto $a$ e o ato são índice do real em jogo na clínica psicanalítica e na formação do psicanalista. Ambos respondem àquilo que dos "afetos imprevisíveis" e "de um desejo inarticulável, a partir de seu lugar, se ajusta [se faire une raison] com uma causa (...) com o mais-de-gozar" (Lacan, 1969/2003, p. 283).

A operância psicanalítica refere-se à "sua parte em jogo", passagem, portanto, da operância psicanalítica para a operância do psicanalista. Destarte, do psicanalista como função, $f(x)$. Então, a primeira questão, a partir desse termo "operância”, é de saber se poderíamos diferenciar radicalmente: o desejo do analista e o ato analítico. Em meu entendimento, ambos apontam para isso que está em jogo na direção da cura.

Como diz Colette Soler: “o desejo do analista, aqui está a fórmula que eu proponho, é o sujeito suposto ao ato analítico" (Soler, 2014, p. 57), afirmando que o desejo do analista é a condição e o suporte do ato possível.

Podemos observar a dimensão temporal do ato do psicanalista, dimensão do instante. Dito instante refere-se ao efeito tíquico, encontro faltoso, entre o que se esperava recolher da última palavra, em uma análise e o que se produz. No que refere ao desejo do analista, o " $x$ " que ele deve manter, ligado ao instante eletivo.

No seminário A política do ato (1999-2000), Colette Soler sustenta que, no que concerne ao analista, o termo do ato não recusa o do desejo. Eu a cito: "Digo que a introdução da expressão 'ato analítico' desloca, no ensino de Lacan, o sentido da expressão desejo do analista" (Soler, 1999-2000, p. 11). Assim, propõe pensar a dimensão do ato vinculada à função - no sentido de Frege, a função $F(x)$ - e adverte que podemos referir-nos à questão do desejo como sendo aquela que responde pelo "ser" do analista. Efetivamente, trata-se da proposta do ser e do des-ser do analista.

A questão da função do analista deve ser entendida pelos resíduos dessa operação: o falo (que refere à Bedeutung do falo) e o objeto $a$. Destarte, entre heteridade e alteridade. Lembro o que Lacan escrevera no Discurso na Escola Freudiana de Paris para aqueles que interrogaram e criticaram sua Proposição: "Assim o desejo do psicanalista é o lugar de onde se está de fora sem pensar nele, mas no qual encontrar-se é ter saído para valer" (Lacan, 1967-/2003b, p. 270). Litoral, então, entre desejo do psicanalista e ato psicanalítico.

O paradoxo do ato psicanalítico incide no desejo do analista. Por causa do ato, ele "faz-se produzir; do objeto $a$; com o objeto $a$ " (Lacan, 1969/2003, p. 375). Esse é objeto que se produz como resto, no final. O que me parece interessante é que, nesses anos que localizamos entre 1964, Fundação de sua Escola, e 1967, ano da Proposição, a proporção áurea lhe serve a Lacan para propor o objeto $a$ na arti- 
culação $1+a$. Portanto, refere-se ao objeto que indica a não totalidade do Um e a infinitude da série. A incomensurabilidade do Outro, pelo objeto $a$, escreve-se: $1+a$. Esse percurso é índice da articulação do objeto causa de desejo e do objeto mais-de-gozar, mais-valia da economia da relação - proporção que não há.

No Resumo do seminário do ato, Lacan escreve:

Se o psicanalisante faz o psicanalista, ainda assim não há nada acrescentado senão a fatura. Para que ela seja devida, é preciso que nos assegurem que há do psicanalista.

É a isso que responde o objeto $a$.

O psicanalista se faz de objeto $a$. Ele se faz, entenda-se: faz-se produzir; do objeto $a$ com o objeto $a$. (Lacan, 1969/2003, p. 375)

Esse objeto $a$, incomensurável, que aponta a incompletude do simbólico $S(\mathbb{A})$, não há Outro do Outro, não há metalinguagem —, não pode ser dito. $\mathrm{O}$ objeto $a$, resíduo da operação da transferência e do engano [meprise] do sujeito suposto saber, com o qual o psicanalista se produz, é indizível. Trata-se de algo que não se articula no nível dos ditos. É a dit-mensão real do objeto, diferente das versões imaginárias do objeto que se leem na fórmula da fantasia e que respondem às substâncias gozantes. Essa definição do objeto faz a borda à incomensurabilidade do 1. Trabalhado nos Seminários 14, 15 e 16, o limite (matemático) que se formula $1+a$ diz respeito à incompletude do Outro. A debilidade da verdade exige uma resposta em termos de saber. Saber que não está no lugar da verdade, mas que aponta o impossível de todo-saber e toda-verdade. Como demonstrar isso em cada caso? O que se transmite desse saber sobre o limite? Lacan já orientara uma resposta ao referir-se ao dizer. Precisamente, é o inaudito que passa nos ditos que será índice desse saber.

No início desse Resumo, Lacan afirma que o ato "tem lugar por um dizer" (Lacan, 1969/2003, p. 371). O objeto $a$ é uma perda real que, atravessada a operação verdade e se presentifica no momento eletivo e tíquico do ato, dito objeto é causa dessa passagem eletiva de psicanalisante a psicanalista. Chamou minha atenção a observação de Colette Soler quando se pergunta, acompanhando esse trecho do Resumo, sobre o que significa que Lacan afirme "não há nada acrescentado senão a fatura". Ela responde que nenhuma virtude pode ser acrescentada, nenhum novo predicado. Se, no início da operação da transferência, temos o sujeito do inconsciente ao qual se supõe um saber, no final temos a produção da causa que operou para o psicanalisante.

Tentemos diferenciar "operar" e "produzir". É pela "operância” que se pode "produzir" esse saber sobre o incomensurável do 1, sobre o indizível e sobre o indecidível. Esse indecidível exige uma nova escolha, diferente daquela que se 
coloca na entrada da transferência. A escolha do final articula, para alguns, o juízo íntimo e a pergunta da sustentação dessa operância, quer dizer: desse lugar do agente no discurso analítico. Ao final, "não há nada mais que um objeto, nada a acrescentar (...). Quando o psicanalisante passa a psicanalista, não há nada a acrescentar. Entendam: nada a acrescentar aos dois elementos da estrutura" (Soler, 1999-2000, p. 139).

A operância do psicanalista articula a aporia e o paradoxo do ato. A aporia indica duas impossibilidades: não podemos ser analisantes de nosso ato, e não podemos ser analistas de nossa análise. Lacan passa dessa aporia para o paradoxo, é isso que propõe para o dispositivo do passe: a transmissão desse paradoxo no qual se trata de obter daquele que se propõe dar seu testemunho após a passagem de analisante a analista: que diga aquilo que não pode dizer.

O paradoxo do ato analítico se atualiza no paradoxo do dispositivo do passe. Cito Colette Soler, nesse Seminário:

O paradoxo do dispositivo do passe é de tentar interrogar o ato analítico a partir do passante, mas sabemos que não há informe possível do ato, que o passante não pode se fazer analisante da sua passagem ao ato analítico. Contudo, o dispositivo busca cernir o ato, não a partir das suas saídas, não do lado das análises concluídas, mas, como diz Lacan, no momento em que se institui no agente, via o testemunho do passante. (Soler, 1999-2000, p. 29)

Não há operância do analista sem o desejo do analista e sem o ato psicanalítico, é uma questão de estrutura. O paradoxo do ato psicanalítico nessa passagem que aponta um saber sobre a causa do desejo é uma disposição ao que se opera com ele. "Na ética que se inaugura pelo ato psicanalítico a lógica manda, isso é certo, por nela encontrarmos seus paradoxos" (Lacan, 1969/2003, p. 376). A operação da transferência e o que ela produz não permite que o ato se acumplicie com a cura-padrão. Contudo, para que uma análise entre em curso, há uma relação de cumplicidade necessária que manifesta a inscientia (ignorância, falta de saber) do sujeito sobre seu desejo e a inscientia do analista sobre o que ele se produziu e sobre o que lhe permite operar. "Com elas nos remete ao tratamento do saber na transferência, tendo como suporte o desejo do analista. Trata-se do não saber constituído como tal, como vazio, como apelo do vazio no centro do saber" (Berta, 2015, p. 164). É essa inscientia que define o saber do psicanalista e que produz o poder agalmático da fala, na cura.

Se o ato não se acumplicia com a cura-padrão, o analista operando com o que ele produziu, por seu ato, tem uma responsabilidade ética. Ele responde desde uma posição bem precisa na sustentação da operação da transferência. 


\section{0 analista em porte-à-faux e o engano do sujeito suposto saber}

No Seminário do ato psicanalítico, na aula de 17 de janeiro de 1968, Lacan, depois de observar que o objeto $a$ é a realização desse tipo de des-ser que atinge o sujeito suposto saber, acrescenta:

(...) o psicanalista sabe ser destinado ao des-ser e que, portanto, o constitui, se posso dizer assim, em um ato em porte-à-faux, já que ele não é o sujeito suposto saber, já que ele não pode sê-lo. E se há alguém que o saiba é, entre todos, o psicanalista. (Lacan, 17/12/1968, inédito)

A expressão porte-à-faux, em arquitetura, indica as instalações que estão sem apoio e que promovem certo balanço. Nelas, o ponto de apoio é um vazio, ali não há mais suporte do que o próprio vazio. Se consideramos que o que opera do psicanalista não é um predicado, mas isso que se produziu, o objeto $a$, concomitante com a dimensão do dizer - precisamente, Lacan abre essa aula de 17 de janeiro dizendo: o ato é, por sua própria dimensão, um dizer —, se consideramos, então, a produção do objeto $a$ (indizível) e o ato definido como dizer, para que ex-sista, o que opera do psicanalista é condição necessária que ele não se apoie no sujeito suposto saber (aqui, há de se localizar a tarefa analisante) e, então, que o analista operando saiba que esse ponto de apoio é um vazio. A operância do psicanalista inclui esse apoio em "porte-à-faux". Isso possibilita que ele saiba onde isso vai dar: "ao de-ser do sujeito suposto saber, a ser apenas o suporte deste objeto que se chama pequeno $a$ " (Lacan, 17/1/1968, inédito). Precisamente, nessa lição de 17 de janeiro de 1968, Lacan retoma o objeto a e o 1, "essa incomensurabilidade, essa relação do pequeno a com o 1 , eis onde se joga o que aparece como realização subjetiva ao fim da tarefa analítica" (Lacan, 17/1/1968, inédito).

No texto “A operância do psicanalista e o desejo em questão" (Berta, 2015), escrevi:

Em 1967 a operância do psicanalista é definida como função lógica $f(x)$. E curiosamente é em 1968-69 - aula de 5 de março de 1969 - que Lacan dirá que no campo do saber, enquanto suposto, é preciso savoir-y-faire com a verdade, como castração. Sim, mas como? Desde uma posição que inclua a tapeação [duperie] (Lacan, 1968-1969/2008, p. 203). Um tapeado é alguém enganado por outro, acrescenta Lacan. Precisamente, sermos tapeados por esse saber, meio de gozo - que tem como irmã a verdade não-toda — sermos tapeados até a goela, pode levar-nos a savoir-y-faire com o desejo como escrita. Capta-se aqui uma modulação no que respeita à presença do analista. Aqui o desejo do analista opera com a produção do objeto $a$. 
O objeto $a$, causa de desejo, mais-de-gozar, agente e semblante no discurso do analista, é um dos nomes da operância do psicanalista. Ele escreve a borda, o limite da série: $1+a$. Produzir o desejo de saber... do impossível, a partir de uma práxis que escreve essa borda, é um dos nomes da clínica psicanalítica. Por essa razão, o analisante segue o saber desde uma posição dupe, e o analista o sustenta desde essa posição porte-à-faux. A partir dela, leva-se em consideração que a verdade sofre do significante [ce qui pâtit du signifiant], e por isso ela está em meio-dizer. É o pathos do significante que determina o porte-à-faux de onde opera o psicanalista. Se qualquer fato só se torna tal a partir do significante, o sujeito depende disso, e a operância do psicanalista, também. Porém, se o significante é semblante, o real está em jogo. A psicanálise é "um discurso sem fala”, como escrevera Lacan no quadro quando dava início a seu Seminário 16: De um Outro ao outro. E por essa trilha já anunciava a dit-mensão e o dizer.

O que não se pode dizer do fato é designado, porém no dizer, por sua falta, e isso que constitui a verdade. É por isso que a verdade sempre se insinua, mas também pode inscrever-se de maneira perfeitamente calculada ali onde só ela tem lugar, nas entrelinhas. A substância da verdade é justamente aquilo que padece por causa do significante - isso vai longe - aquilo que padece pela natureza dele, digamos. (Lacan, 1968-1969/2008, p. 65)

Isso posto, saber da posição em porte-à-faux permite fazer passar do "ato em falso" [uma das traduções dessa expressão porte-à-faux] e oferecer condições à contingência do ato, pois além de o sujeito saber o que está em jogo [en-je] em uma análise é "que o psicanalista tem que se igualar à estrutura que o determina (...) em sua posição de sujeito tal como inscrita no real: tal inscrição é o que define propriamente o ato" (Lacan, 1967/2003c, p. 339). Aqui, temos o antecedente do que será dito posteriormente sobre o sujeito real quando Lacan formaliza a clínica a partir do borromeano.

\section{Do passe}

No “Discurso na Escola Freudiana de Paris” (1967/2003b), discurso esse que Lacan fizera a partir das críticas à sua "Proposição", discurso contemporâneo ao que tinha afirmado em seu Seminário sobre o ato analítico (1967-1968), Lacan escreve: "O inconsciente, por sua vez, não joga com o semblante. E o desejo do Outro não é um querer na falta” (Lacan, 1967/2003b, p. 287). Nem semblante nem querer enodam inconsciente e desejo. Isso se acompanha melhor se consideramos que esse discurso foi escrito na esteira de sua afirmação surpreendente, naquele momento: o inconsciente, saber sem sujeito. O desejo do Outro não é um querer na falta, o desejo do Outro é alteridade perante a qual, após a travessia da fantasia, há de se tomar posição, e responder por ela, ou, melhor dito: saber fazer com ela aí. 
Isso está em questão no passe.

A questão refere-se não só ao testemunho do passante e à sua transmissão pelos passadores, mas à elaboração de cada cartel do passe.

Escrevi sobre isso no texto que apresentei na Jornada de Escola, em setembro de 2017, que aconteceu no Rio de Janeiro (Berta, 2018, pp. 14-18). Nessa ocasião, diferenciava o corte da dedução, acompanhando as elaborações de Lacan e os aportes de nosso colega Michel Bousseyroux (2014, p. 68). São os efeitos dos cortes produzidos pelo não sentido e pela não relação o que se transmite no testemunho. Isso tem um efeito na elaboração de um cartel do passe.

Porém, e se um dizer se infere dos ditos, se os efeitos do dizer se inferem dos ditos, eu noto que, no trabalho de elaboração dos cartéis do passe dos quais participei, isso também esteve em jogo. A elaboração posterior ao encontro com os passadores, a partir do que eles passaram do testemunho dos passantes, não foi um trabalho imediato. A discussão do cartel e mesmo os argumentos que se apresentam para os demais colegas do Colegiado Internacional da Garantia, após a decisão do cartel, têm um efeito de ensino, com o sem nomeação.

Portanto, o corte que perpasse o esp-do-laps e que se infere do testemunho, além de escutar o mal-entendido [malentendu], assinala algo que gostaria de partilhar, a modo de questão que teremos de continuar trabalhando. Retomo aqui o que muito me interessou em um debate recente que tivemos no Fórum São Paulo por ocasião da primeira apresentação da AE, Adriana Grosman. A partir de uma pergunta, ela respondeu que, no testemunho, a história da qual se tenta testemunhar se descompleta. A Hystoire se descompleta, disse a ela nesse debate. Trata-se de um movimento que não podemos tomar como modelo. Apenas se produz, caso se produza. Isso tem efeitos no cartel e em seu trabalho de elaboração. Não se trata de um testemunho organizado ou desorganizado, é apenas a descompletude que se transmite. É a infinitude latente que pode ou não ser evocada nessa passagem do testemunho. Há, de fato, um paradoxo para testemunhar da verdade mentirosa, porque a tendência é fazer desse testemunho uma nova verdade. É possível que esse saber sobre a descompletude coadune com os afetos do fim e que isso se transmita. É possível que a "certeza do fim” não ofusque essa disposição ao ato psicanalítico e à operância em questão e por vir.

\section{Concluindo}

Facultar ao sujeito sua verdade que sofre do significante é bem diferente de convocá-lo a dizer a verdade. Por aí se estabelece e se indica que a operância psicanalítica se sabe em porte-à-faux. Dita operância leva em consideração que o inconsciente joga com efeitos da linguagem, mas que é saber sem sujeito, que a insciência é signo do saber insabido, que o dejeto da operação analítica é concomitante ao 
engano do sujeito suposto saber, que é com a produção da causa real do objeto $a$ que "há do analista" [il y a du psychanalyste] poder operar, que a contingência do ato terá lugar se o que opera leva em conta essa posição particular que hoje friso com a expressão "porte-à-faux". A seguridade que o sujeito obtém da fantasia treme na entrada e no final da análise. Essa é a travessia. Daí, advém, às vezes, o desejo do analista a ser escrito como " $x$ " e com o qual, espera-se, que se opere na direção da cura. Essa é uma disposição ao inconsciente, uma vez que, se os analistas fazem parte do inconsciente, eles devem operar, com o inconsciente saber sem sujeito, como causa. E, mesmo, para aquele que o decida, pôr à prova isso a partir do testemunho dado à Escola. 


\section{Referências bibliográficas}

Berta, S. (2015). A operância do psicanalista e o desejo em questão. Heteridade 11: Revista de Psicanálise da IF-EPFCL, 164-169. Obtido em 9 de março de 2018. Recuperado de https://champlacanien.net/public/docu/4/heterite11.pd

Berta, S. (2018). $F(x) A M E$. Wunsch 18. Boletim Internacional da Escola de Psicanálise dos Foros do Campo Lacaniano. Obtido em 24 de junho de 2018. Recuperado de http://www.champlacanien.net/public/docu/4/wunsch18.pdf Bousseyroux, M. (2014). El passe por borromeo. Wunsch 14, Dez., 68-71.

Lacan, J. (1965-1966). O seminário, livro 13: o objeto da psicanálise. Inédito.

Lacan, J. (1967-1968). O seminário, livro 15: o ato psicanalítico. Aula de 22 de novembro de 1967. Inédito.

Lacan, J. (1967/2003a). Proposição de 9 de outubro de 1967 sobre o psicanalista da Escola. In J. Lacan. Outros escritos (Vera Ribeiro, Trad.) (pp. 248-264). Rio de Janeiro: Jorge Zahar.

Lacan, J. (1967/2003b). Discurso na Escola Freudiana de Paris. In J. Lacan. Outros escritos (Vera Ribeiro, Trad.) (pp. 265-287). Rio de Janeiro: Jorge Zahar.

Lacan, J. (1967/2003c). O engano do sujeito suposto saber. In J. Lacan. Outros escritos (Vera Ribeiro, Trad.) (pp. 329-340). Rio de Janeiro: Jorge Zahar.

Lacan, J. (1968-1969/2008). O seminário, livro 16: de um Outro ao outro (Vera Ribeiro, Trad.). Rio de Janeiro: Jorge Zahar.

Lacan, J. (1969/2003). O ato psicanalítico. Resumo do seminário de 1967-1968. In J. Lacan. Outros escritos (Vera Ribeiro, Trad.) (pp. 371-379). Rio de Janeiro: Jorge Zahar.

Soler, C. (1999-2000). La politique de l'acte. Cours du Collège Clinique de Paris. Diffusion: Fancis Ancibure, Miguel Bosch et Mariví Galan. Paris.

Soler, C. (2014). Humanisation? Cours 2013-2014. Collection: Études, cours 2013-2014. Édition du Champ lacanien.

Recebido: 11/06/2018

Aprovado: 11/06/2018 